\title{
高速度カメラと光電管によるライン プロフイルの連続測定の方法*
}

浜田繁雄・横田昌厇・(日大理工)
内芯田垈次郎・吉村久光

The idea and principle of the method is described and discussed. The image is not swept along an arelike film surface as in usual high speed cameras, but is scanned repeatedily at one place. The plane mirrors are arranged tangentially on an eliiptical surface. The exit sit and the rotating mirror are set in the position of the foci of this elIipse. Thus the image of the line profile is scanned at the sit each : time the light beam sweeps across one of the plane mirrors. However, the image plane rotates with the rotating mirror, so a narrow width sit is not suitabie for this instrument. Therefore, one knife edge of the exit slit is fixed in the focussing plane and the sit width made greater than the length of the inage so that the signal from the photomultiplier is independent of the rotation of the image plane. The signal. will indicate the integrated light intensity of the image. The output signal from the photomultiplier is fed to the

* The Method of Continuous Observation of Line Profile by High Speed Camera and Photomuliplier.

※ S.Hamada, M.Yokota, T.Uchida and H.Yoshimura. Department of Physics, College of Science and Engeneering, Nihon University. 
differential circuits. Thus the signal through this circuit indicates the real Iine profile.

§1. はじめに

プラズマから出る光を分光して、時間的に追い乍ら测定しようこする時、光量が大変に落ちる。

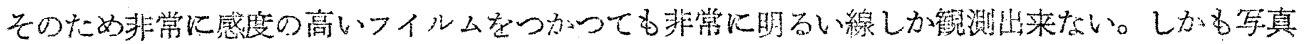
を利用しようとすると、フオトメトリーの手続に可成の努力をくりかえさなければならない。こ のためなるべく光電管でやりたいが、光電管にすると測定量が 1 ビットで、写真のフイルムのよ うに币と㢱さの時間的変化を同時にみるというわけにはいかない。そのため光電管で 2 ビット以 上の情報量をあつか抢うとするとこんどは光電管と楖定系の数がふえてくる。このやり方の例は ステラレーターに用いられたタンデム・エタロンによる線けの測定でわる。）光電子增倍管を沢山

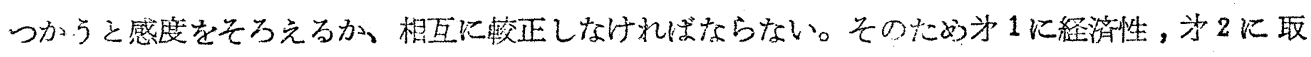
扱いの簡単さを考元て次の様なやり方にすることにしだ。それは線のプロフイルを像面の上でく りかえし走查させ、そのくりか克しの1回の走查時間を現象の変化時間上り充分速くすれば、1 本の光電管で巾と強度が理続的にとりだせる。

像を振動させるということにだけ注目すれば、1つの方法は光学系の分散系の周折率を急速に

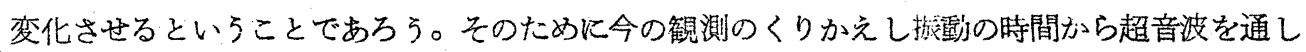
た透明な液体に光のビームを音波の半波長に対して無視出来る程の巾にして通す。しかし乍ら之 は技術的に見て毎秒数百万回の測定は国難である。と云うのは数百乃サイクルの音波が得られて もとの波長は極短に短かくなつてしまうからである。光学系の分散部の大部分を一様にかえる方 法はまだないようである。そこで観測の速度から考えて、高速カメラを使うのがよいということ になる。

畐転をくりかえし運動に直すやり方として次のようにする。橹円鏡の一方の焦点から出る光は 他の焦点に集まるので、一方の焦点に迴転鏡を置き、他の焦点にスリットを置く。スリットの所

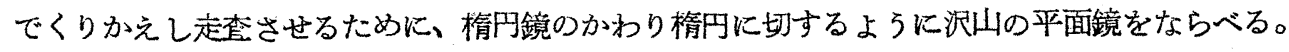

平面鏡の場所によつて入射角がわずかに変るので、像は焦点の所でくりかえし走査することに なる。 
§2. 基碦になる理届

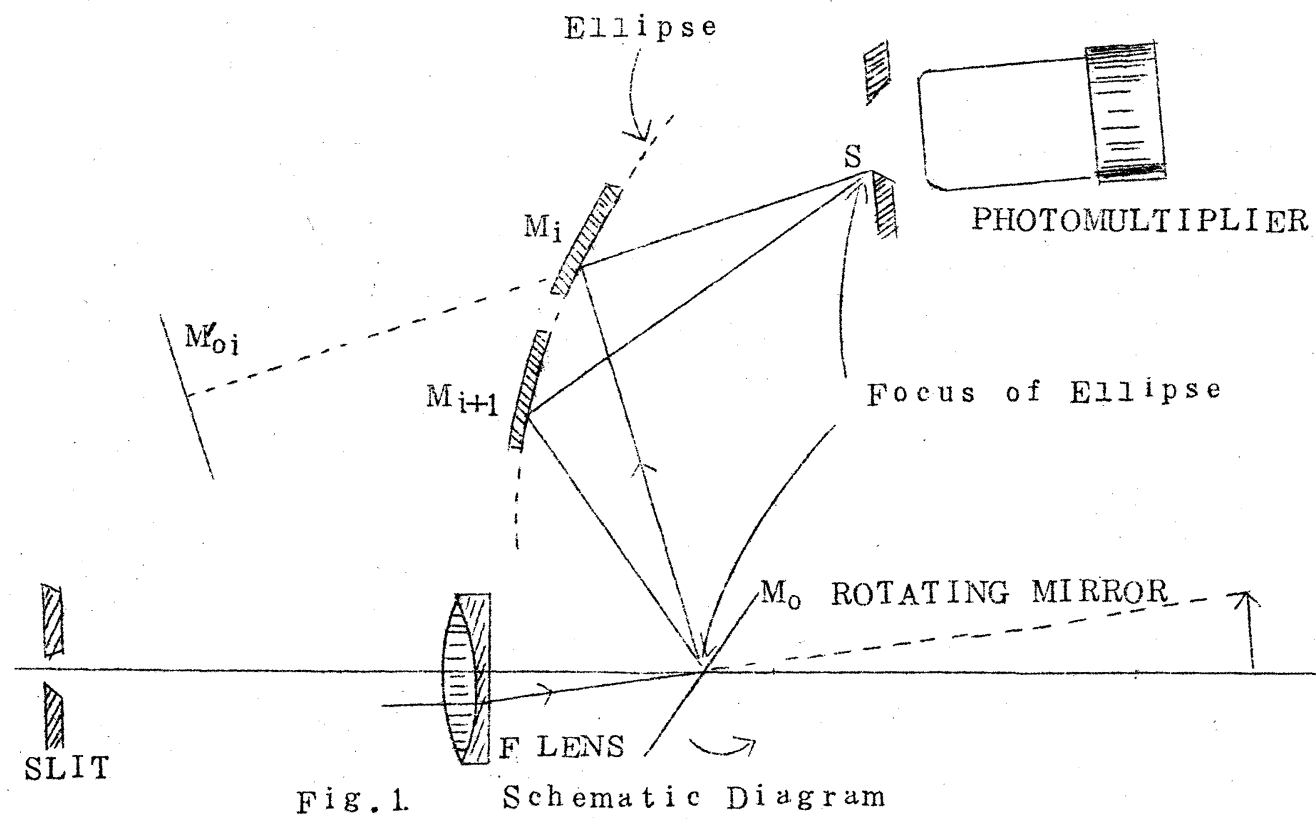

矛 1 図に示すよ5にレンズFを通り廻転鏡 $M_{0}$ によつて反射された光は $M_{0}$ の廹転軸と、スリ ットSを焦点とする梅円上に和かれた鏡の $1 つ \mathrm{M}_{\mathrm{i}}$ によつて反射され、スリットSに達する。 $\mathrm{S}$ からみるとこの光は $\mathrm{M}_{\mathrm{i}}$ に関して対称な位置にある $\mathrm{M}_{0}$ の虚像 $\mathrm{M}_{0 \mathrm{i}}^{\prime}$ から反射されて来るように 見える。従つてFによる像は $\mathrm{M}_{0}$ の迴転角速度の 2 倍の角速度で $\mathrm{S}$ の上をはしる。 $\mathrm{M}_{0}$ による反 射光が $\mathrm{M}_{\mathrm{i}}$ そ過ざると次の镜 $\mathrm{M}_{\mathrm{i}+1}$ によつて同じことがくりかえされる。

(i) $\mathrm{M}_{\mathrm{j}}$ の位置 (为 2 圀)

$\mathrm{F}$ の焦点と $\mathrm{M}_{0}$ との距離を $\mathrm{A}$ とれば

$$
a_{i}+b_{i}=A
$$

となるような棈円の接線上に $\mathrm{M}_{\mathrm{i}}$ を䈯かなければならない。ベクトル $\overrightarrow{\mathrm{c}}($ 迴転鏡の軸とスリット を結ぶベクトル)とレンズ $\mathrm{F} の$ 光軸の角を $\Phi, \overrightarrow{\mathrm{c}}$ と $\mathrm{a}_{\mathrm{i}}\left(\mathrm{M}_{0}\right.$ の軸から $\mathrm{M}_{\mathrm{i}}$ の中点へ向うべクトル) との角を $\theta_{i} ， \mathrm{M}_{0}$ と $\mathrm{F}$ の光軸の間の角をひとしよう。また $\mathrm{M}_{\mathrm{o}}$ がない時の $\mathrm{F}$ の像点 $\mathrm{P}$ が $\mathrm{M}_{0}$ と $\mathrm{M}_{\mathrm{i}}$ によってスリット $\mathrm{S}$ 上に結ばれているとし，Pと Fの光軸との距離を $\mathrm{x} ， \mathrm{x}$ の最大值をXと しょう。(このわけは、像はスリットの上を走查していき、sIit の中に像の光がらえていく ことを示すためである。） 
浜田・橫田・内田・吉村

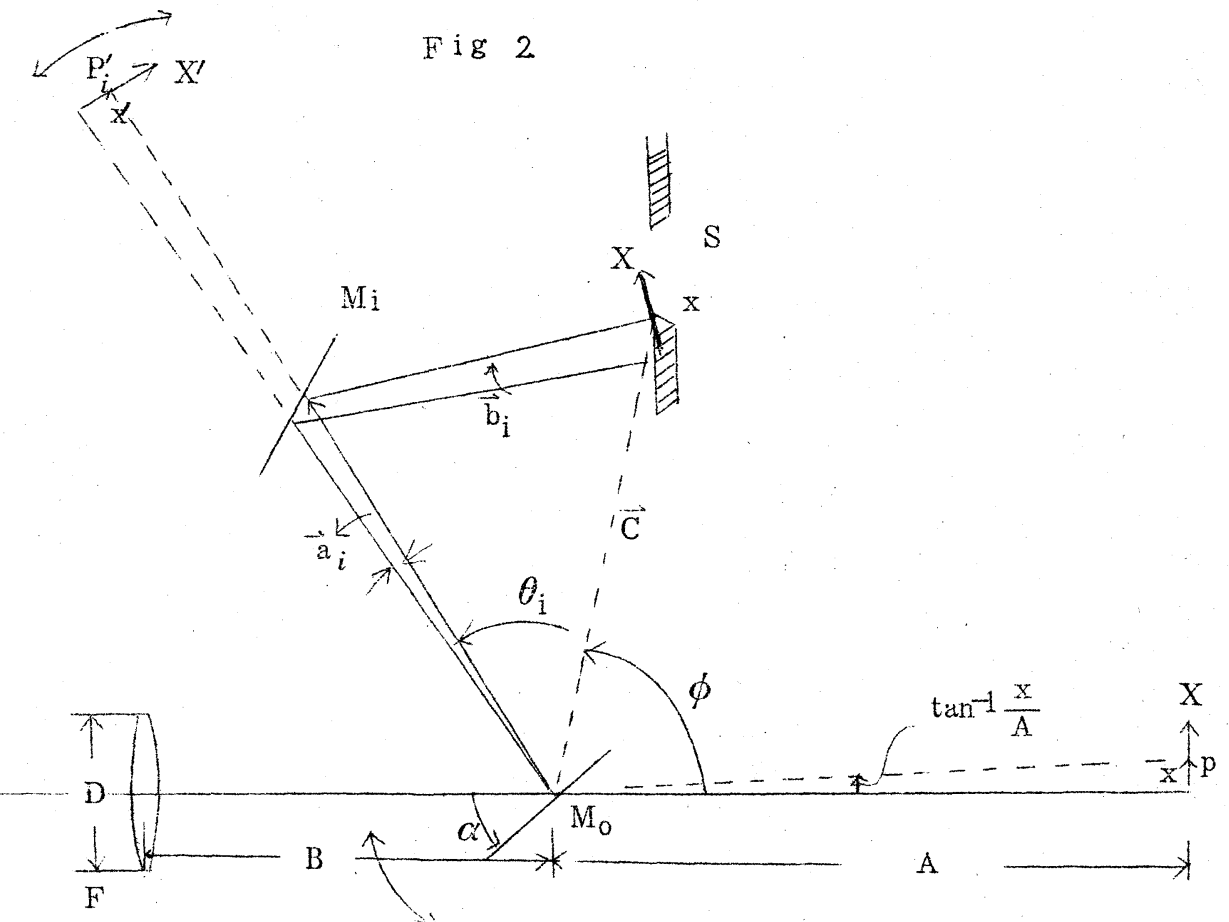

このとさ

$$
\alpha=\frac{1}{2}\left(\theta_{\mathrm{i}}+\phi+\tan ^{-1} \frac{\mathrm{x}}{\mathrm{A}}\right)
$$

或㤝

$$
x=A \tan \left(2 \alpha-\theta_{i}-\phi\right)
$$

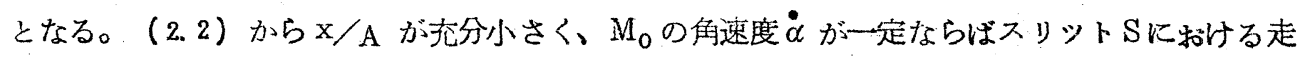
查速度は一定であることが分る。次に鏡 $\mathrm{M}_{\mathrm{i}}$ によつて $\mathrm{x}=\mathrm{X}$ なる像が $\mathrm{S}$ に結ばれた時鏡 $\mathrm{M}_{\mathrm{i}+1}$ に よつてx=-X なる像が $\mathrm{S}$ に結ばれるように、 $\theta_{i+1}$ を定めよう。このとき（2.1）から

$$
\theta_{i+1}+\phi-\tan ^{-1} \frac{X}{A}=\theta_{i}+\phi+\tan ^{-1} \frac{X}{A}
$$

故に

$$
\theta_{\mathrm{i}+1}-\theta_{\mathrm{i}}=2 \tan ^{-1} \frac{\mathrm{X}}{\mathrm{A}}=\Delta \theta
$$


高速度カメラと光電管によるラインプロフイルの連続則定の方法

従つて各鏡の $\mathrm{M}_{0}$ に関する角距離は等間隔である。仮りに $\mathrm{A}=50 \mathrm{~cm} \quad \mathrm{X}=2.5 \mathrm{~mm}$ とすると

$$
\theta_{i+1}-\theta_{i}=\frac{1}{100} \text { radian }
$$

になる。従つて $\mathrm{M}_{0}$ の呬転速度が $10^{5} \mathrm{Radian} / \mathrm{sec}($ ベックマン高速カメラ)であるとすると、 $0.1 \mu$ sec 每以工ine profi工を取るこ之が出来る。

ii) スリットSに入る光の傾さ

スリットSが例えばスペクトル線のプロフイルの像の巾よりもせまい時にはスリットと $\vec{b}_{\mathrm{i}}$ と の傾さによつて光量が変る。この椂な光量の変化は小さい方がよい。今棈円上の任意の点をQ

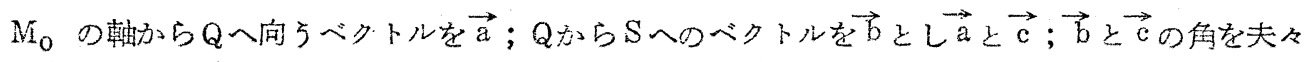
$\theta$ ，クとすると(为与図)

a

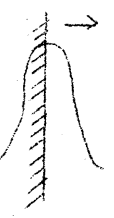

b

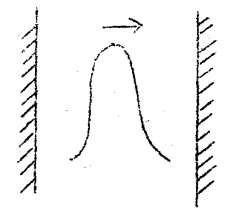

c

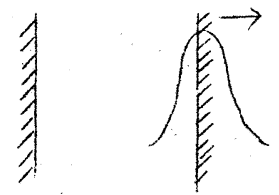

S L I T

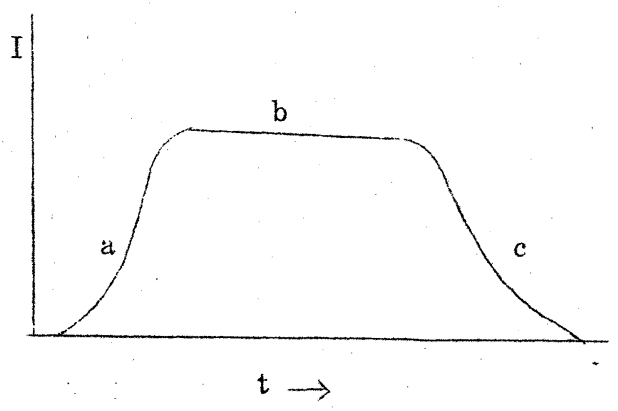

THE SIGNAL FROM PHOTOMUT I PL I ER

Fig. 3.

$$
\frac{d \eta}{d \theta}=-\frac{A^{2}-c^{2}}{A^{2}+c^{2}-2 A c \cos \theta}
$$

なる関釈がある。この式から点Qが $\mathrm{M}_{0}$ の近くにある時の方が $\left|\frac{\mathrm{d} \eta}{\mathrm{d} \theta}\right|$ が小さいことが結論される れる。従つて鏡 $\mathrm{M}_{\mathrm{i}}$ はなるべく $\mathrm{M}_{0}$ の近くに配置した方がよい。同じ理由で c゙を $\mathrm{A}$ に近した方が $\left|\frac{\mathrm{d} \eta}{\mathrm{d} \theta}\right|$ が小さいからなるべく細長い饰円をえらんだ方がよい。 
iii）スリットSに達する光量

スリットSに達する光量はどの鏡 $\mathrm{M}_{\mathrm{i}}$ についても一定で、しかも出来るだけ大きくなければな らない。この条件を満足するため炕はつの方法がある。一つはSからみた鏡 $\mathrm{M}_{\mathrm{i}}$ の視角をすべ て等しくし、他方 $\mathrm{M}_{0}$ による $\mathrm{P}$ の像 $\mathrm{Pi}^{\prime}$ に集まる光束の中に常に $\mathrm{M}_{\mathrm{i}}$ 泣含まれるようにすること である。 $\mathrm{M}_{\mathrm{i}}$ のSに対する視角を $\Delta \eta$ とすると

(2.4) から

$$
\Delta \eta \leq \frac{\mathrm{A}^{2}-\mathrm{c}^{2}}{\mathrm{~A}^{2}+\mathrm{c}^{2}-2 \mathrm{Ac} \cos \theta_{\mathrm{N}}} \cdot \Delta \theta
$$

でなければならない。ここで Suffix $N$ は $N$ ケの鏡のうちで最も $M_{0}$ に近い鏡を示するの とする。 $\Delta \theta$ は (2.3) で与えら就る゙、荚は（2.3）は像の大きさXで定まる $\Delta \theta$ の最小值を与 えているにすぎない。 $M_{0}$ の角速度をのとすると

$$
\tau=\frac{\Delta \theta}{\omega} \geq \frac{2}{\omega} \tan ^{-1} \frac{\mathrm{X}}{\mathrm{A}}
$$

は繰返し走査の週期を与穴る。従つててが長くてもよければ $\Delta \theta$ は大きく取ることが出来る。

(2.6)を使つて（2.5）から $\triangle \theta$ を消去すると、

$$
\Delta \eta \leq \frac{\mathrm{A}^{2}-\mathrm{c}^{2}}{\mathrm{~A}^{2}+\mathrm{c}^{2}-2 \mathrm{Ac} \cos \theta_{\mathrm{N}}} \omega_{\tau}
$$

を得る。（2.5）＇は走査週期てを短くすれば光量を䧧牲にしなければならぬことを示している。 序に鏡の数Nは

$$
N=\frac{\theta_{N}-\theta_{1}}{\Delta \theta}=\frac{\theta_{N}-\theta_{1}}{\tau \omega} \leq \frac{\pi}{2 \tan ^{-1} \frac{\mathrm{X}}{\mathrm{A}}}
$$

で押えられる。次にレンズ $\mathrm{F}$ の直径を $\mathrm{D}, \mathrm{F}$ と $\mathrm{M}_{0}$ の距離を $\mathrm{B}$, 鏡 $\mathrm{M}_{0}, \mathrm{M}_{\mathrm{i}}$ の長さを夫々 $\ell_{0}$ ， として、 $\ell_{0}$ 及びDの最小值を求めょう。 $\mathrm{P}_{\mathrm{i}}$ から出て $\mathrm{M}_{\mathrm{i}}$ を含を光束は常に $\mathrm{M}_{0}$ に含まれる必

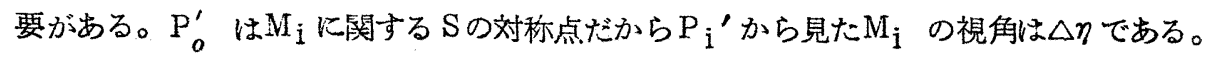
従つて $\frac{x}{A}$ そ無視すると

$$
\Delta \eta \leq \frac{\ell_{0}}{\mathrm{~A}} \sin \frac{1}{2}\left(\phi+\theta_{1}\right) \leq \frac{\ell_{0}}{\mathrm{~A}} \sin \frac{1}{2}\left(\phi+\theta_{\mathrm{i}}\right)
$$

或は

$$
\ell_{0} \geq \frac{A \Delta \eta}{\sin \frac{1}{2}\left(\phi+\theta_{1}\right)}
$$


高速度カメラと光電管によるラインプロフイルの連続測定の方法

を得る。

$$
\begin{aligned}
& \text { Dについては } 1 \ll \frac{\mathrm{X}}{\mathrm{D}} \text { として } \\
& \mathrm{D} \geq \frac{\mathrm{A}+\mathrm{B}}{\mathrm{A}} \ell_{0} \sin \frac{1}{2}\left(\phi+\theta_{\mathrm{N}}\right)
\end{aligned}
$$

を得る。

以上の方法は $M_{\mathfrak{i}}$ を一種のスリットとみて各々の鏡の寸法を定めていに達する光量を一定にし たことに相当する。もう一つの方法は $M_{1}$ の寸法は（2.6）で定まる $\Delta \theta$ で定め、レンズFの直 後にしぼりスコットを扎いて光量を一定にする仕方である。この方が技埱的に容易であろう。し ぼりスリットの内をdとする。 $\mathrm{P}_{i}$ に対する光束 開きは $\frac{\mathrm{d}}{\mathrm{A}+\mathrm{B}}$ である。この光速が常に $M_{i} に ふ く$ れればよい。（この光束は当然 $M_{0}$ にもるくまれねばならない。）それ故先づ $\ell$ は

$$
\ell_{0} \gtrsim \frac{A}{A+B} \frac{d}{\sin \frac{1}{2}\left(\phi+\theta_{1}\right)}
$$

でなければならない。次に（2.4）によつて

$$
\frac{d}{A+B} \leq \frac{A^{2}-c^{2}}{A^{2}+c^{2}-2 A c \cos \theta_{N}} \quad \Delta \theta=\frac{\left(A^{2}-c^{2}\right) \omega \tau}{A^{2}+c^{2}-2 A \cos \theta_{N}}
$$

を得る。この式と（2.5)'を比較すると明るさに差はない。をた（2.10）と(2.8)を比較すれば 同じ明るさを得るために必要なと。も大差ないことが判る。徒つて技術的な容易さからみて为二 の方法が優れている。

\section{§3. スリットについて}

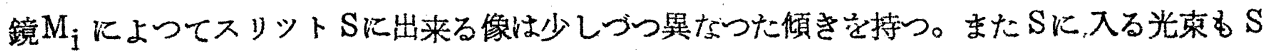
に対して少しづつ巽なつた入射角を持つている。従つてせまいスりットを使う時は、入射角につ いての補正が必要である。所がスベクトルラインのプロフイルのウより広いスリットを使用すれ ば入射角の補正は不必要である。此時はFig.3.と示寸様に、フオトマルの Out put はプ. ロフイルの䆅分曲線となる。この。ut put を微分回路に入れてやれば、プロフイルそのるの をオッシログラフ上に描ける。るう一回微分すれば、最大微係数を持位置の間の線巾が求まる。 ガウス型のプロフイルの場合は半巾とこの巾は簡単な関係にある。 
§4. 出わり $わ$

以上簡単に方法の原則的なことだけを示した。この他実際の設計に当つては像の大ささ、焦点

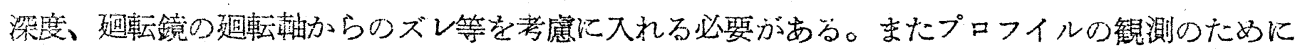
は分散系 (エタロンを便うのがよいであるう) の明るさ、フオトマルの感度等について詳しい㭘 討が必要であるが、それ等は別の機会にゆずる。この装置は単にプロフイルの観測のみでなく、 例えば、誘瞋ピンチに上つて出来るプラズマ柱の半径方向の光度分布を流し写真のフォトメトり 一によるよりも正確且つ容易に調べることが出来よう。更にフイルターを使用寺れば一算詳しい データーを取ることが出来る。

1) C.R. Burnett Controlied Thermonuclear Conference HeIded Washington D.C., Feb.1958.p. 472. 